- Faktor - faktor Yang Mempengaruhi Kinerja Transaksi Berjalan Indonesia

- Indonesian Japan Economic Relations : (Investment and Trade)

- Analisis Kinerja Industri TPT Indonesia

- Kajian Atas Perlakuan Akuntansi Terhadap Skema Perdagangan Emisi (Emission Trading Scheme) Pelajaran Dari Uni Eropa dan Australia

- Kajian Kebijakan PPN Atas Bahan Bakar Minyak Untuk Kapal Tujuan Internasional (Study on Value Added Tax Policy on International Bunker Fuen

\begin{tabular}{|c|c|c|c|c|c|}
\hline Kaj. Eko. \& Keu. & Vol. 14 & No. 4 & Jakarta 2010 & $\begin{array}{c}\text { ISSN 1410- } \\
3249\end{array}$ & $\begin{array}{c}\text { Terakredthasi B } \\
\text { (No. Akreditasi : } \\
\text { 306/AU2/P2mBI/0B/2010) }\end{array}$ \\
\hline
\end{tabular}




\section{K A J I A N}

ERONOMI

REUANGAN

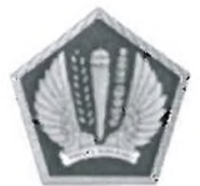

Pusat Kebijakan Ekonomi Makro

Badan Kebijakan Fiskal

Kementerian Keuangan RI

圆

Faktor-faktor Yang Mempengaruhi Kinerja Transaksi

Berjalan Indonesia

㺼

Indonesia Japan Economic Relations: (Investment and Trade)

?

Analisis Kinerja Industri TPT Indonesia

酸

Kajian Atas Perlakuan Akuntansi Terhadap Skema

Perdagangan Emisi (Emission Trading Scheme)

Pelajaran dari Uni Eropa dan Australia

Kajian Kebijakan PPN Atas Bahan Bakar Minyak Untuk Kapal

Tujuan Internasional (Study On Value Added Tax Policy On Internasional Bunker Fuel)

\begin{tabular}{|l|l|l|l|l|}
\hline Kaj. Eko. \& Keu. & Vol. 14 & No.4 & Jakarta 2010 & ISSN 1410-3249 \\
\hline
\end{tabular} 


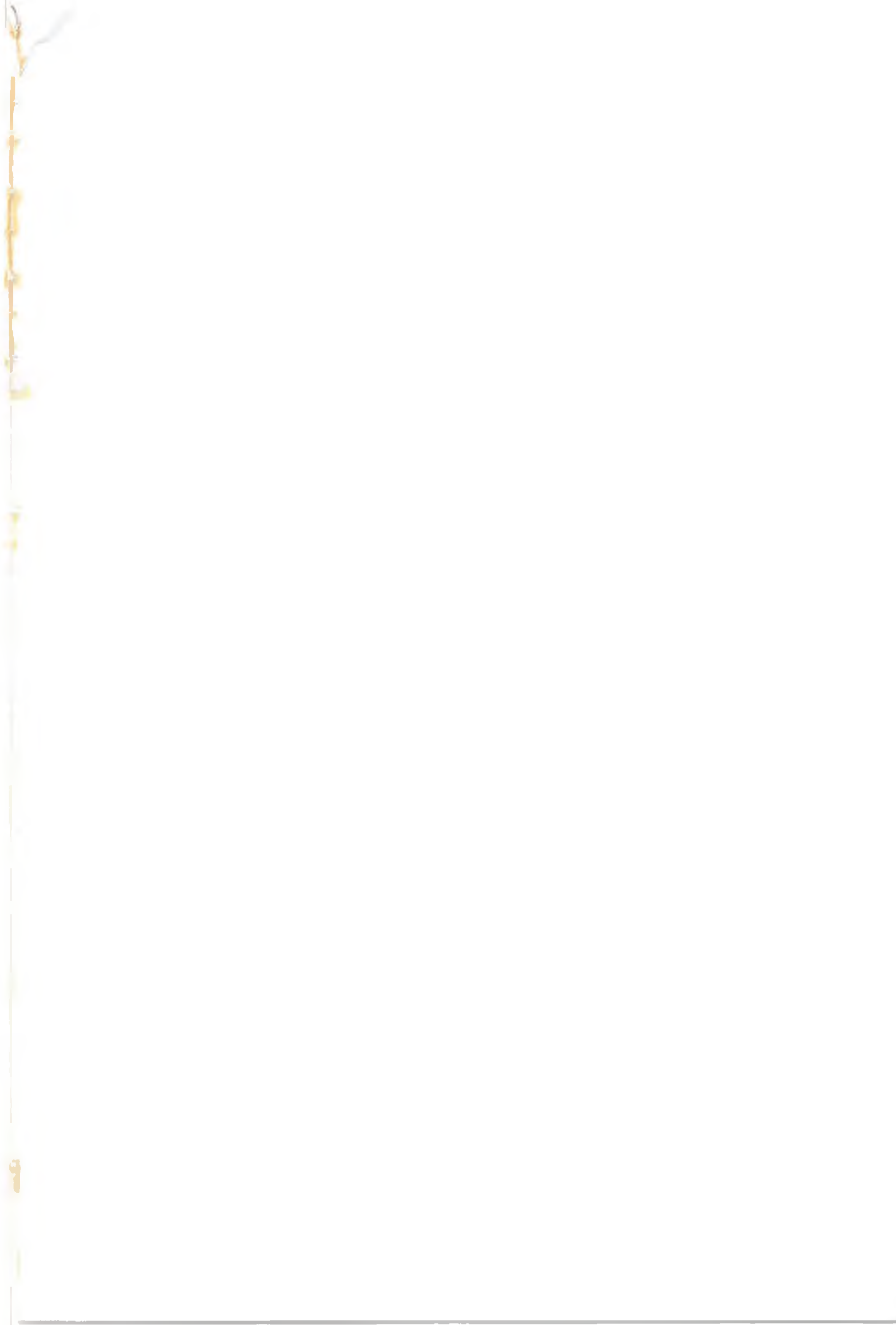




\section{KATA SAMBUTAN}

Kami panjatkan rasa syukur kepada Tuhan Yang Maha Esa atas terbitnya Kajian Ekonomi dan Keuangan edisi ini ke hadapan pembaca sekalian. Pada edisi ini, kami menyajikan berbagai topik yang berkaitan dengan analisis dan dampak kebijakan publik di bidang ekonomi dan keuangan negara.

Kajian pada volume kali ini diisi oleh berbagai topik tulisan yaitu FaktorFaktor yang Mempengaruhi Kinerja Transaksi Berjalan Indonesia; Indonesia Japan Economic Relations:(Investment and Trade); Analisis Kinerja Industri TPT Indonesia; Kajian Atas Perlakuan Akuntansi Terhadap Skema Perdagangan Emisi (Emission Trading Scheme) Pelajaran Dari Uni Eropa Dan Australia; dan Kajian Kebijakan PPN Atas Bahan Bakar Minyak Untuk Kapal Tujuan Internasional (Study On Value Added Tax Policy On Internasional Bunker Fuel). Adapun para penulis yang berkontribusi pada penerbitan kali ini yaitu Rudi Handoko, Suparman Zen Kemu, Ragimun, Mahpud Sujai, dan I Nyoman Widia.

Demikianlah kata pengantar yang dapat kami sampaikan. Ibarat peribahasa tiada gading yang tak retak, maka kami menyadari kajian ini tentunya masih terdapat kekurangan baik yang disengaja maupun yang tidak kami sengaja. Oleh karena itu, kami mengharapkan masukan dari para pembaca guna perbaikan di masa yang akan datang. Selanjutnya, kami berharap jurnal ini dapat memberikan manfaat kepada para pembaca sekalian. Selamat membaca!

Jakarta, 2010

Dewan Redaksi 


\section{DAFTAR ISI}

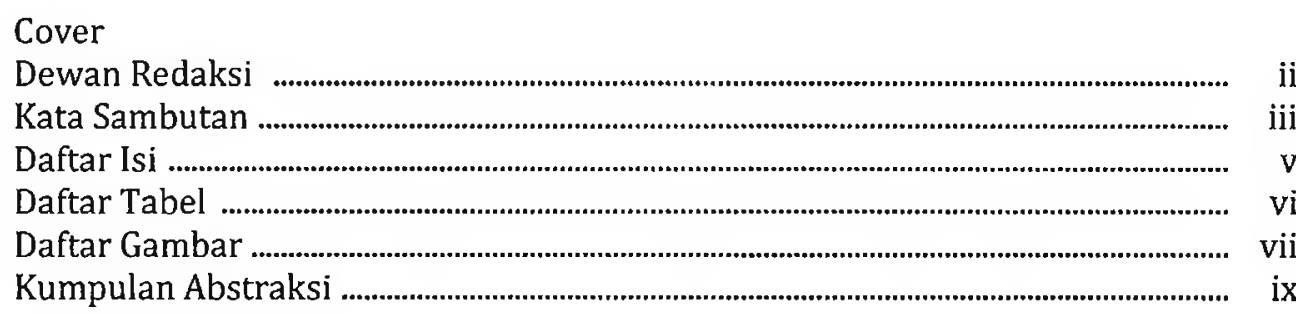

FAKTOR-FAKTOR YANG MEMPENGARUHI KINERJA TRANSAKSI

BERJALAN INDONESIA

Oleh: Rudi Handoko

INDONESIA JAPAN ECONOMIC RELATIONS:

(INVESTMENT AND TRADE)

Oleh: Suparman Zen Kemu

\section{ANALISIS KINERJA INDUSTRI TPT INDONESIA}

Oleh: Ragimun

\section{KAJIAN ATAS PERLAKUAN AKUNTANSI TERHADAP SKEMA \\ PERDAGANGAN EMISI (EMISSION TRADING SCHEME) \\ PELAJARAN DARI UNI EROPA DAN AUSTRALIA}

Oleh: Mahpud Sujai

KAJIAN KEBIJAKAN PPN ATAS BAHAN BAKAR MINYAK

UNTUK KAPAL TUJUAN INTERNASIONAL (STUDY ON VALUE ADDED

TAX POLICY ON INTERNATIONAL BUNKER FUEL)

Oleh: I Nyoman Widia 


\section{DAFTAR TABEL}

INDONESIA JAPAN ECONOMIC RELATIONS: (INVESTMENT AND TRADE)

Tabel 2.1. Japanese Foreign Investment Destination

\section{ANALISIS KINERJA INDUSTRI TPT INDONESIA}

Tabel 3.1. Profil Industri TPT Indonesia tahun 2004-2008...................................... 50

Tabel 3.2. Program Peningkatan Kinerja Industri TPT ............................................. 53

Tabel 3.3. Faktor-Faktor Yang Mempengaruhi Daya Saing Industri TPT Indonesia dengan China 57

Tabel 3.4. Struktur Biaya Tekstil dan Produk Tekstil (\%) 58

KAJIAN ATAS PERLAKUAN AKUNTANSI TERHADAP SKEMA PERDAGANGAN EMISI (EMISSION TRADING SCHEME) PELAJARAN DARI UNI EROPA DAN AUSTRALIA

Tabel 1.1. GHG Emissions Summary(MtCO2e) 66

\section{KAJIAN KEBIJAKAN PPN ATAS BAHAN BAKAR MINYAK} UNTUK KAPAL TUJUAN INTERNASIONAL (STUDY ON VALUE ADDED TAX POLICY ON INTERNASIONAL BUNKER FUEL)

Tabel 1.1. Penerimaan Perpajakan 2005 - 2010 (Triliun Rupiah) 78

Tabel 3.1. Perbandingan Penjualan BBM Indonesia dan Singapura (kilo liter) 83 


\section{DAFTAR GAMBAR}

\section{FAKTOR-FAKTOR YANG MEMPENGARUHI KINERJA TRANSAKSI BERJALAN INDONESIA}

Gambar 3.1. Neraca Transaksi Berjalan dan Neraca Perdagangan 1960 - 1979

(US\$ juta)

Gambar 3.2. Ekspor Minyak dan Bukan Minyak 1960 - 1979

(US\$ juta)

Gambar 3.3. Neraca Transaksi Berjalan dan Neraca Perdagangan 1980 - 1991 (US\$ juta)

Gambar 3.4. Ekspor Minyak dan Gas 1980 - 1991 (US\$ juta) 10

Gambar 3.5. Komponen Neraca Transaksi Berjalan 1992 - 2003 (US\$ juta)

Gambar 3.6. Neraca Transaksi Berjalan dan Neraca Perdagangan 1992 - 2003 (US\$ juta)

Gambar 3.7. Neraca Transaksi Berjalan dan Neraca Perdagangan Q1 2004 - Q2 2010 (US\$ juta)

Gambar 3.8. Neraca Transaksi Berjalan dan Neraca Perdagangan Non Migas Q1 2004 - Q2 2010 (US\$ juta) 14

Gambar 3.9. Neraca Transaksi Berjalan dan Neraca Perdagangan Migas Q1 2004 - Q2 2010 (US\$ juta)

Gambar 3.10. Neraca Transaksi Berjalan dan Neraca Perdagangan Minyak Q1 2004 - Q2 2010 (US\$ juta)

Gambar 3.11. Neraca Transaksi Berjalan dan Neraca Perdagangan Gas Q1 $2004-$ Q2 2010 (US\$ juta)

Gambar 3.12. Neraca Transaksi Berjalan dan Jasa-jasa Q1 2004 - Q2 2010 (US\$ juta) 17

Gambar 3.13. Neraca Transaksi Berjalan dan Pendapatan Q1 2004 - Q2 2010 (US\$ juta) 18

Gambar 3.14. Neraca Transaksi Berjalan dan Transfer Q1 2004 - Q2 2010 (US\$ juta) 18

Gambar 3.15. Hubungan Transaksi Berjalan dan Pertumbuhan Ekonomi Domestik

Gambar 3.16. Hubungan Transaksi Berjalan dan Pertumbuhan Ekonomi Dunia

Gambar 3.17. Transaksi Berjalan dan Harga Komoditas. 21

Gambar 3.17. Transaksi Berjalan dan Nilai Tukar 22 
INDONESIA JAPAN ECONOMIC RELATIONS:

(INVESTMENT AND TRADE)

Graph 2.1. Indonesian non-oil exports by destination country (US\$ billion)

Graph 2.2. Indonesia Japanese import and export

(Billion Yen)

\section{ANALISIS KINERJA INDUSTRI TPT INDONESIA}

Grafik 3.1. Jumlah Perusahaan dan Jumlah Share Industri TPT

Tahun 2008-2009 


\begin{tabular}{|c|}
\hline $\begin{array}{l}\text { MAJALAH KAJIAN EKONOMI DAN KEUANGAN } \\
\text { ISSN 1410-3249 } \\
\text { KEK Terakreditasi B } \\
\text { (No. Akreditasi : 306/AU2/P2MBI/08/2010) } \\
\text { Volume 14 Nomor 4 Tahun } 2010\end{array}$ \\
\hline $\begin{array}{c}\text { Keywords used are free terms. Abstracts can be reproduced without } \\
\text { permission or charge. }\end{array}$ \\
\hline ABSTRAKSI \\
\hline $\begin{array}{l}\text { Handoko, Rudi, et. al. (Badan Kebijakan Fiskal, Kementerian Keuangan) } \\
\text { Faktor-Faktor Yang Mempengaruhi Kinerja Transaksi Berjalan Indonesia } \\
\text { Kajian Ekonomi dan Keuangan Volume } 14 \text { Nomor } 4 \text { Tahun 2010, halaman } \\
\text { 1-24 }\end{array}$ \\
\hline $\begin{array}{l}\text { This paper attempt to describe factors affecting the performance of current } \\
\text { account in Indonesia. Current account performance is showed by surplus or } \\
\text { deficit position. Analysis of the factors is conducted based on periodization of } \\
\text { current account performance. Other analysis was carried out by using scatter } \\
\text { graph to show the relationship between two variables in question. The results } \\
\text { show that some factors affecting current account performance are global } \\
\text { economic growth, Indonesian major trading partners growth, domestic } \\
\text { economic growth, international commodities prices, exchange rate } \\
\text { management, economic policy, and financial crisis. } \\
\text { Keyword: current account, balance of payment, externalsector, trade } \\
\text { balance }\end{array}$ \\
\hline $\begin{array}{l}\text { Zen Kemu, Suparman, et. al. (Badan Kebijakan Fiskal, Kementerian } \\
\text { Keuangan) } \\
\text { Indonesia Japan Economic Relations: (Investment and Trade) } \\
\text { Kajian Ekonomi dan Keuangan Volume } 14 \text { Nomor } 4 \text { Tahun 2010, halaman } \\
25-40\end{array}$ \\
\hline $\begin{array}{l}\text { Pra krisis ekonomi 1998, Indonesia merupakan Negara urutan ketiga dalam } \\
\text { tujuan investasi langsung Jepang (FDI), dibawah China dan Amerika Serikat. } \\
\text { Namun, paska krisis ekonomi } 1998 \text { tersebut, posisi Indonesia turun ke } \\
\text { ranking kedelapan dan telah dilewati oleh India, Thailand, Vietnam, Rusia, } \\
\text { dan Brazil. Beberapa faktor yang menyebabkan terjadinya hal ini adalah: } \\
\text { kondisi infrastruktur yang buruk di dalam negeri terutama masalah } \\
\text { perlistrikan, kurangnya kepastian hukum, adanya pajak berganda, fluktuasi }\end{array}$ \\
\hline
\end{tabular}




\begin{tabular}{|c|}
\hline $\begin{array}{l}\text { MAJALAH KAJIAN EKONOMI DAN KEUANGAN } \\
\text { ISSN 1410-3249 } \\
\text { KEK Terakreditasi B } \\
\text { (No. Akreditasi : 306/AU2/P2MBI/08/2010) } \\
\text { Volume 14 Nomor } 4 \text { Tahun } 2010\end{array}$ \\
\hline $\begin{array}{l}\text { Keywords used are free terms. Abstracts can be reproduced without } \\
\text { permission or charge. }\end{array}$ \\
\hline ABSTRAKSI \\
\hline $\begin{array}{l}\text { nilai tukar rupiah yang terlampau tajam, dan lemahnya hubungan antar } \\
\text { industrI (linkage). Dalam perdagangan luar negeri Jepang merupakan } \\
\text { partner dagang terbesar Indonesia. Pada tahun 2007, total perdagangan } \\
\text { Indonesia Jepang mencapai nilai USD 23,6, merupakan yang terbesar di } \\
\text { ASEAN dibandingkan perdagangan Negara anggota ASEAN lainnya } \\
\text { terhadap Jepang. Namun jenis ekspor Indonesia ke Jepang di dominasi oleh } \\
\text { komoditi dasar seperti minyak bumi, gas, bahan tambang, dan produk kayu. } \\
\text { Sementara ekspor Negara anggota ASEAN yang lain ke Jepang seperti } \\
\text { Singapura, Thailand dan Malaysia didominasi produk manufaktur berupa } \\
\text { komponen yang mempunyai nilai tambah lebih tinggi. Gejala lainnya adalah } \\
\text { bahwa ada tendensi peningkatan nilai perdagangan Indonesia dengan dua } \\
\text { Negara Asia Timur yaitu China dan Korea. Hal ini positif bagi Indonesia } \\
\text { namun kurang baik bagi kelanjutan hubungan ekonomi Indonesia Jepang. } \\
\text { Berbagai masalah ini perlu dibicarakan secara lebih serius oleh kedua } \\
\text { Negara agar nilai perdagangan dan investasi Indonesia Jepang dapat lebih } \\
\text { meningkat lagi. }\end{array}$ \\
\hline $\begin{array}{l}\text { Ragimun, et. al. (Badan Kebijakan Fiskal, Kementerian Keuangan) } \\
\text { Analisis Kinerja Industri TPT Indonesia } \\
\text { Kajian Ekonomi dan Keuangan Volume } 14 \text { Nomor } 4 \text { Tahun 2010, halaman } \\
\text { 41-62 }\end{array}$ \\
\hline $\begin{array}{l}\text { Textile industry can be categorized the oldest industry in Indonesia. This is a } \\
\text { significant industry, which provides not only on economic contribution but } \\
\text { also on absorbing employment for the total } 15 \% \text { of all manufacture sectors. } \\
\text { At the present, textile industry is facing some structural problems, such as the } \\
\text { high cost of energy, insufficient of infrastructure, the low technology and } \\
\text { well-worn of the machines, and also the overflowing of China's textiles into } \\
\text { Indonesia markets. Those are causing high cost of production and further } \\
\text { impeding competitiveness of domestic textile in the world market. } \\
\text { On the early stage, the textile industry development was boosted by the } \\
\text { Foreign Investment Law (1967) and the Domestic Investment Law (1968). In } \\
\text { addition, the export quota system grows up steadily during the period of } \\
1984 \text { to } 2000, \text { which reach to } 18,5 \% \text { per year. For the last } 5 \text { years, however, } \\
\text { the export shows a fluctuation. For } 2000 \text {, the number reaches US\$8.3 billion, } \\
\text { and in } 2009 \text { goes to US } \$ 9.26 \text { billion or just a tiny increase of } 3.41 \% \text { per year. }\end{array}$ \\
\hline
\end{tabular}




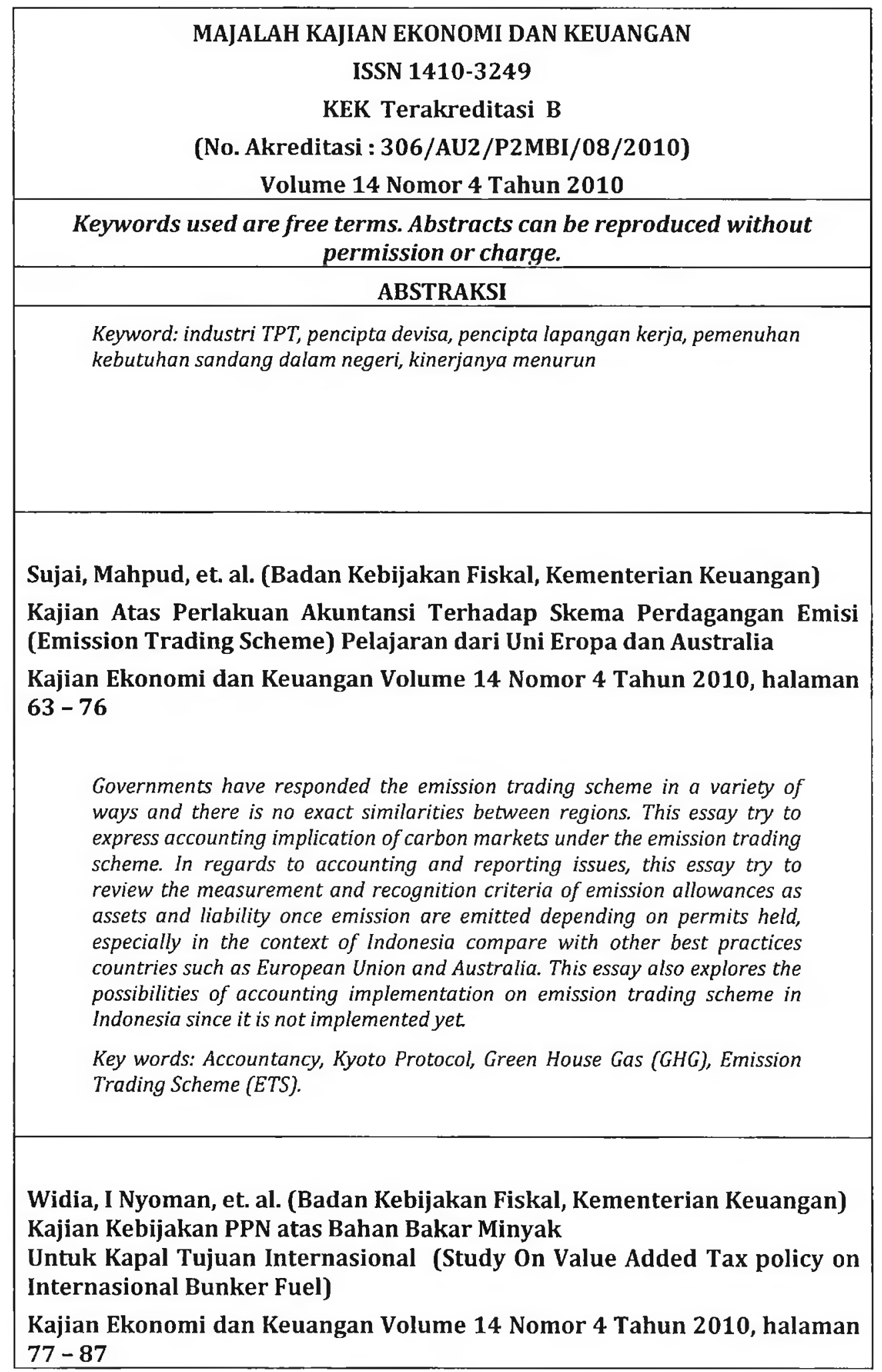


MAJALAH KAJIAN EKONOMI DAN KEUANGAN

ISSN 1410-3249

KEK Terakreditasi B

(No. Akreditasi : 306/AU2/P2MBI/08/2010)

Volume 14 Nomor 4 Tahun 2010

Keywords used are free terms. Abstracts can be reproduced without permission or charge.

ABSTRAKSI

This study focus on value added tax policy on international bunker fuel. Current regulation in Indonesia describes that government has imposed value added tax $10 \%$ on bunker fuel. Qualitative Approach was used in this study. As a result, imposing value added tax on bunker fuel against the international best practice. According to Value Added Tax Law, Government of Indonesia may give an incentive on bunker fuel.

Keywords: value added tax, international bunker fuel, incentive 


\title{
KAJIAN KEBIJAKAN PPN ATAS BAHAN BAKAR MINYAK UNTUK KAPAL TUJUAN INTERNASIONAL (STUDY ON VALUE ADDED TAX POLICY ON INTERNASIONAL BUNKER FUEL)
}

\author{
Oleh:
}

I Nyoman Widia ${ }^{1}$

\begin{abstract}
This study focus on value added tax policy on international bunker fuel. Current regulation in Indonesia describes that government has imposed value added tax $10 \%$ on bunker fuel. Qualitative Approach was used in this study. As a result, imposing value added tax on bunker fuel against the international best practice. According to Value Added Tax Law, Government of Indonesia may give an incentive on bunker fuel.
\end{abstract}

Keywords: value added tax, international bunker fuel, incentive

\section{PENDAHULUAN}

\subsection{Latar Belakang}

Pajak memegang peranan penting dalam penerimaan negara. Hampir tiap tahun penerimaan pajak dalam Anggaran Pendapatan dan Belanja Negara (APBN) mengalami peningkatan. Kalau pada tahun 2005 realisasi penerimaan perpajakan dalam APBN mencapai Rp347,03 triliun, angka ini melonjak menjadi Rp619,92 triliun dalam tahun 2009, dan dalam APBN-P 2010 dinaikkan menjadi Rp743,33 triliun. Sementara itu, realisasi Pajak Dalam Negeri pada tahun 2005 berjumlah Rp331,80 triliun, sedangkan relaisasi pada tahun 2009 meningkat drastis menjadi Rp601,25 triliun, serta dalam APBN-P 2010 naik menjadi 720,76 triliun.

Salah satu jenis pajak dalam penerimaan perpajakan adalah Pajak Pertambahan Nilai (PPN). Realisasi penerimaan PPN dari tahun ke tahun hampir selalu mengalami peningkatan juga. Apabila tahun 2005 realisasi penerimaan PPN berjumlah Rp101,30 triliun, realisasi pada tahun 2009 meningkat menjadi Rp193,07 triliun, dan dalam tahun 2010 ditargetkan mencapai Rp262,97 triliun. Khusus untuk penerimaan PPN di sektor hilir migas, realisasi penerimaan tahun

\footnotetext{
${ }^{\prime}$ Kasubbid pada Pusat Kebijakan Pendapatan Negara, Badan Kebijakan Fiskal, Kementerian Keuangan
} 
2005 mencapai 11,06 triliun. Jumlah ini meningkat lebih dari dua kali lipat pada tahun 2009, yakni mencapai Rp23,49 triliun (lihat Tabel 1.1).

Tabel 1.1. Penerimaan Perpajakan 2005 - 2010

(Triliun Rupiah)

\begin{tabular}{|l|r|r|r|r|r|r|}
\hline \multicolumn{1}{|c|}{ Uraian } & 2005 & 2006 & 2007 & 2008 & 2009 & $2010^{*}$ \\
\hline $\begin{array}{l}\text { Penerimaan } \\
\text { Perpajakan }\end{array}$ & 347,03 & 409,20 & 490,99 & 658,70 & 619,92 & 743,33 \\
\hline $\begin{array}{l}\text { Pajak Dalam } \\
\text { Negeri }\end{array}$ & 331,80 & 395,97 & 470,05 & 622,36 & 601,25 & 720,76 \\
\hline $\begin{array}{l}\text { Pajak } \\
\text { Pertambahan } \\
\text { Nilai }\end{array}$ & 101,30 & 123,04 & 154,53 & 209,65 & 193,07 & 262,97 \\
\hline $\begin{array}{l}\text { PPN Migas } \\
\text { (Hilir) }\end{array}$ & 11,06 & 9,84 & 23,94 & 34,87 & 23,49 & - \\
\hline $\begin{array}{l}\text { PPh Migas } \\
\text { (Hilir) }\end{array}$ & 6,67 & 20,76 & 6,60 & 9,07 & 7,14 & - \\
\hline
\end{tabular}

Sumber: Kementerian Keuangan, 2010

*Tahun $2010=$ APBN-P, tahun lainnya = realisasi

Untuk mencapai target penerimaan perpajakan yang terus meningkat, pemerintah senantiasa berupaya dan melakukan langkah-langkah yang mendukung upaya pencapaian target tersebut. Salah satunya adalah upaya memperbaiki kebijakan di bidang perpajakan. Kebijakan-kebijakan yang diambil tidak hanya berorientasi pada target penerimaan jangka pendek, tetapi juga kebijakan yang mendukung semakin kondusifnya iklim usaha di Indonesia. Dengan semakin kondusifnya iklim usaha, maka dalam jangka panjang penerimaan perpajakan juga akan meningkat. Salah satu kebijakan di bidang Pajak Pertambahan Nilai (PPN) yang perlu dilakukan kajian adalah kebijakan PPN atas penyerahan bahan bakar minyak untuk kapal tujuan internasional.

\subsection{Perumusan Masalah}

Atas penyerahan BBM kapal laut untuk tujuan internasional saat ini masih dipungut PPN sebesar 10\% dari harga jual. Akibatnya, harga yang harus dibayar menjadi lebih mahal. Oleh karena itu, kapal-kapal yang mengangkut barang untuk tujuan internasional lebih memilih mengisi bahan bakar di luar negeri, seperti Singapura dan Malaysia. Apabila pungutan PPN dihapus, maka harga BBM di 
Indonesia akan mampu bersaing dengan negara lain, sehingga kapal-kapal tujuan internasional akan memilih membeli BBM di Indonesia.

\subsection{Tujuan}

Kajian ini bertujuan:

a. Untuk menganalisis kebijakan PPN atas Bahan Bakar Minyak untuk kapal tujuan internasional yang berlaku saat ini.

b. Untuk menganalisis perlakuan PPN atas Bahan Bakar Minyak untuk kapal tujuan internasional yang berlaku di negara lain untuk kemudian dibandingkan dengan kebijakan yang berlaku di Indonesia.

c. Untuk menganalisis peraturan yang berlaku yang memungkinkan Pemerintah menghapuskan PPN atas Bahan Bakar Minyak untuk kapal tujuan internasional.

\subsection{Landasan Teori}

Berdasarkan faktor yang sangat dominan untuk menentukan timbulnya kewajiban pajak, jenis pajak dibedakan menjadi Pajak Subjektif dan Pajak Objektif. Pajak Subjektif adalah jenis pajak yang kewajiban pajaknya sangat ditentukan pertama-tama oleh keadaan subjektif dari subjek pajak. Contohnya adalah Pajak Penghasilan. Dalam Pajak Objektif, timbulnya kewajiban pajak sangat ditentukan pertama-tama oleh objek pajak. Keadaan subjek pajak menjadi tidak relevan, walaupun dalam kasus-kasus tertentu ikut dipertimbangkan. Contoh kelompok ini adalah Pajak Pertambahan Nilai. ${ }^{1}$

Sebagai bentuk pungutan negara, Pajak Pertambahan Nilai (PPN) mempunyai beberapa karakteristik yang membedakan dengan jenis pajak lainnya. Sebagai pajak atas konsumsi umum dalam negeri, PPN hanya dikenakan atas konsumsi Barang Kena Pajak dan/atau Jasa Kena Pajak yang dilakukan di dalam negeri. ${ }^{2}$ Hal ini berarti PPN hanya dikenakan terhadap konsumsi di dalam negeri, sedangkan kalau barang dan/atau jasa dikonsumsi di luar negeri, maka tidak akan dikenakan PPN.

Menurut Untung Sukardji, ${ }^{3}$ PPN menganut prinsip tempat tujuan (destination principle). Berdasarkan prinsip ini, barang impor akan menanggung beban pajak yang sama dengan barang produksi dalam negeri. Karena keduanya sama-sama dikonsumsi di dalam negeri, maka akan dikenakan pajak dengan beban yang sama. Sebaliknya, barang produksi dalam negeri yang akan diekspor tidak dikenakan PPN karena akan dikenakan PPN di negara tempat tujuan barang, yaitu negara tempat komoditi ekspor tersebut akan dikonsumsi.

Di samping untuk mengisi kas negara (fungsi budgetair), pajak juga mempunyai fungsi untuk mengatur (fungsi regulerend) yang disebut juga sebagai 
fungsi tambahan, yaitu pajak juga dipergunakan oleh pemerintah sebagai alat untuk mencapai tujuan tertentu. Disebut fungsi tambahan karena fungsi ini hanya sebagai pelengkap dari fungsi utama pajak, yakni fungsi budgetair. ${ }^{4}$ Menurut R. Santoso Brotodihardjo, 5 fungsi mengatur ini digunakan di luar bidang keuangan dan banyak ditujukan kepada sektor swasta. Dalam hal Pajak Pertambahan Nilai, fungsi mengatur ini dijalankan melalui pemberian fasilitas kepada Wajib Pajak.

Melalui fungsi mengaturnya, pajak dapat dipergunakan untuk mengatur dan mengarahkan masyarakat ke arah yang dikehendaki oleh Pemerintah. Pemerintah dapat mendorong kegiatan masyarakat agar sejalan dengan program yang telah dicanangkan. Dorongan pemerintah ini dapat dilakukan melalui pemberian insentif perpajakan (tax incentive). ${ }^{6}$ Salah satu jenis insentif pajak yang dapat diberikan Pemerintah adalah insentif atau fasilitas Pajak Pertambahan Nilai.

Berdasarkan Pasal 16B Undang-Undang Nomor 8 Tahun 1983 Tentang Pajak Pertambahan Nilai Barang dan Jasa dan Pajak Penjualan atas Barang Mewah sebagaimana telah beberapa kali diubah terakhir dengan Undang Undang Nomor 42 Tahun 2009 (selanjutnya dalam karya tulis ini disebut UU PPN), fasilitas PPN diberikan dalam bentuk PPN terutang tidak dipungut sebagian atau seluruhnya dan PPN dibebaskan untuk sementara waktu atau selamanya. ${ }^{7}$ Perbedaan mendasar dari kedua bentuk fasilitas ini terletak pada perlakuan atas Pajak Masukan, yaitu PPN yang dibayar pada saat memperoleh Barang Kena Pajak atau Jasa Kena Pajak. Jika fasilitasnya berupa PPN tidak dipungut, maka Pajak Masukannya dapat dikreditkan. Sebaliknya, Pajak Masukan tidak dapat dikreditkan apabila fasilitasnya berupa PPN dibebaskan.

Dalam Penjelasan Pasal 16B UU PPN tersebut di atas disebutkan bahwa tujuan utama diberikannya fasilitas perpajakan adalah untuk berhasilnya sektor kegiatan ekonomi yang mempunyai prioritas tinggi dalam skala nasional, mendorong perkembangan dunia usaha dan meningkatkan daya saing, mendukung pertahanan nasional, serta memperlancar pembangunan nasional. Fasilitas yang diatur menurut pasal ini diberikan terbatas pada hal-hal tertentu saja. Salah satunya adalah dalam rangka menampung kemungkinan perjanjian dengan negara lain dalam bidang perdagangan dan investasi, konvensi internasional yang telah diratifikasi, serta kelaziman internasional lainnya. ${ }^{8}$ Rumusan ini baru muncul dalam Undang-Undang Nomor 42 Tahun 2009 yang mulai berlaku tanggal 1 April 2010, sedangkan dalam Undang-Undang sebelumnya diatur bahwa fasilitas diberikan dalam rangka menampung kemungkinan perjanjian dengan negara atau negara-negara lain dalam bidang perdagangan dan investasi. 


\section{METODOLOGI}

\subsection{Waktu dan Tempat}

Kajian dilakukan selama bulan Maret sampai dengan Oktober 2010 di Jakarta.

\subsection{Cara Pengumpulan Data}

Menurut Farouk Muhammad, ${ }^{9}$ teknik pengumpulan data yang digunakan dalam penelitian kualitatf adalah wawancara mendalam, observasi partisipasi, focus group discussion, dan analisis dokumen. Dalam penelitian ini, wawancara mendalam dilakukan dengan pegawai Pertamina, khususnya VP Pemasaran Industri \& Marine Pertamina beserta staf. Sementara itu, diskusi kelompok terarah (focus group discussioan) dilakukan dengan pihak-pihak yang terkait seperti Pertamina, Kementerian Perhubungan, Indonesian National Shipowners' Association (INSA), dan Diretorat Jenderal Pajak. Pengumpulan data juga dilakukan dengan cara mencari data dan informasi melalui internet, buku-buku referensi, dan peraturan-peraturan di bidang perpajakan.

\subsection{Metode Analisis Data}

Analisis berarti mengolah data, mengorganisir data, memecahkannya dalam unit-unit yang lebih kecil, mencari pola dan tema-tema yang sama. ${ }^{10}$ Oleh karena itu, dalam penelitian ini analisis dan penafsiran (interpretatif) senantiasa berjalan beriringan. Adapun metode yang digunakan dalam menganalisis data adalah teknik analisis interpretatif yang bersifat deskriptif. Pertama-tama analisis dilakukan dengan menggunakan teori-teori yang ada. Berdasarkan teori-teori yang ada dan yang relevan, kemudian analisis dilakukan dengan cara mencari perbandingan perlakuan perpajakan sejenis di negara-negara lain (kelaziman internasional). Selanjutnya, analisis dilakukan melalui kajian terhadap peraturan-peraturan yang ada (kajian hukum).

\section{HASIL DAN PEMBAHASAN}

\subsection{Kebijakan PPN atas BBM Kapal untuk Tujuan Internasional yang Berlaku Saat Ini}

Atas penyerahan Bahan Bakar Minyak (BBM) untuk kapal tujuan internasional saat ini masih dikenakan PPN sebesar 10\% dari harga jual. Pengenaan PPN ini membawa konsekuensi harga BBM di Indonesia menjadi lebih mahal dibandingkan di negara lain, seperti Singapura dan Malaysia. Hal ini karena 
di beberapa negara sudah tidak mengenakan PPN atas BBM kapal laut tujuan internasional, termasuk di Singapura dan Malaysia.

PPN merupakan pajak atas konsumsi barang dan jasa di dalam negeri. Artinya, barang atau jasa yang dikonsumsi di luar negeri tidak akan dikenakan PPN. Dalam kaitannya dengan bahan bakar minyak untuk kapal tujuan internasional terdapat hal yang menarik. Setelah mengisi bahan bakar di pelabuhan Indonesia, kapal-kapal tujuan internasional meninggalkan perairan Indonesia menuju luar negeri. Bahan bakar yang dibeli di Indonesia itu tidak dikonsumsi lagi di dalam daerah pabean Indonesia. Walaupun penyerahan BBM dilakukan di Indonesia, tetapi lokasi untuk memanfaatkan barang/atau jasa berada di luar Indonesia. Oleh karena itu, pemungutan PPN atas BBM ini sepintas terlihat kurang tepat karena BBM tersebut tidak dikonsumsi di dalam daerah pabean Indonesia.

Sementara itu, dalam destination principle, PPN dikenakan di negara tempat barang itu dikonsumsi. Karena BBM itu tidak dikonsumsi di Indonesia, maka menjadi kurang tepat apabila Indonesia mengenakan PPN atas penyerahan BBM kapal internasional tersebut. Di pihak lain, BBM untuk kapal mempunyai karakteristik yang berbeda dengan komoditas lainnya, seperti barang elektronik. Ekspor barang elektronik tidak dikenakan PPN, tetapi PPN akan dikenakan di negara tujuan ekspor. Sebaliknya, BBM kapal itu dikonsumsi di sepanjang perjalanan kapal di laut, bukan di daratan. Apabila tidak dikenakan PPN pada saat penyerahan di Indonesia, maka atas konsumsi BBM ini akan terbebas sama sekali dari pungutan PPN.

Berdasarkan kedua teori di atas (pajak atas konsumsi di dalam negeri dan destination principle), pengenaan PPN atas bahan bakar minyak untuk kapal tujuan internasional adalah tepat. Sebelum 1 April 2010 Pemerintah juga tidak bisa memberikan fasilitas, baik berupa PPN tidak dipungut ataupun PPN dibebaskan. Dalam Penjelasan Pasal 16B Undang-Undang Nomor 18 Tahun 2000 Tentang Perubahan Keduan Undang-Undang Nomor 8 Tahun 1983 Tentang Pajak Pertambahan Nilai Barang dan Jasa dan Pajak Penjualan atas Barang Mewah disebutkan bahwa salah satu kriteria dalam memberikan fasilitas PPN adalah dalam rangka menampung kemungkinan perjanjian dengan negara atau negaranegara lain dalam bidang perdagangan dan investasi. Hal ini berarti untuk memberikan fasilitas PPN atas bahan bakar minyak untuk kapal tujuan internasional masih memerlukan persyaratan adanya perjanjian dengan negara lain. Indonesia tidak pernah mengadakan perjanjian khusus dengan negara lain tentang bahan bakar minyak ini. Oleh karena itu, Pemerintah tidak bisa memberikan fasilitas PPN atas penyerahan bahan bakar minyak untuk kapal tujuan internasional. Ketentuan ini berlaku hingga tanggal 31 Maret 2010. 


\subsection{Kebijakan di Negara Lain}

Sejak 1 Januari 2005 negara Singapura menerapkan skema baru dalam pemungutan pajak (GST = Goods and Services Tax). Skema ini dinamakan Approved Marine Fuel Trader Scheme (Approved MFT). ${ }^{11}$ Berdasarkan aturan ini Pemerintah Singapura tidak mengenakan pajak atas Approved Marine Fuel Trade (MFT). Dengan tidak dikenakannya GST atas penyerahan Approved MFT ini, maka hargaharga BBM untuk keperluan bunker internasional dapat bersaing dengan negara lain.

Jika dibandingkan dengan Indonesia, penjualan Singapura jauh di atas Indonesia. Dalam tahun 2007 Singapura mampu menjual sebanyak 31.500 .000 kilo liter, sedangkan Indonesia hanya menjual sebesar 1.321 .983 kilo liter. Ketimpangan yang besar ini berlanjut ke tahun 2008. Jumlah penjualan Indonesia menurun menjadi 1.121 .734 kilo liter, sedangkan Singapura meningkat menjadi 34.900.000. Kejadian yang sama berlanjut dalam tahun 2009. Penjualan Singapura makin meningkat menjadi 36.400 .000 , sedangkan Indonesia makin menurun menuju angka 890.706 kilo liter.

Tabel 3.1. Perbandingan Penjualan BBM

Indonesia dan Singapura (kilo liter)

\begin{tabular}{|c|c|c|c|}
\hline Negara & $\mathbf{2 0 0 7}$ & $\mathbf{2 0 0 8}$ & $\mathbf{2 0 0 9}$ \\
\hline Indonesia & 1.321 .983 & 1.121 .734 & 890.706 \\
\hline Singapura & 31.500 .000 & 34.900 .000 & 36.400 .000 \\
\hline
\end{tabular}

Sumber: Pertamina, 2010.

Malaysia juga menerapkan kebijakan yang sama. Atas barang yang tidak dikonsumsi di dalam negeri, tidak akan dikenakan pajak. Demikian juga atas bahan bakar untuk kapal tujuan internasional. Perlakuan atas bahan bakar ini dipersamakan dengan komoditi ekspor. Harga BBM di Malaysia menjadi lebih kompetitif dibandingkan dengan harga di Indonesia. Sebagai contoh, para pemilik kapal yang membawa barang-barang dari Pelabuhan Belawan, Medan lebih memilih untuk mengisi bahan bakar di Malaysia.

Di negara Korea Selatan, bahan bakar minyak untuk transportasi internasional (baik untuk pesawat udara maupun kapal laut) dipersamakan dengan barang yang diekspor. Pemerintah Korea Selatan memberikan insentif dengan mengenakan Pajak Pertambahan Nilai (Value Added Tax) sebesar 0\%. Pemberian insentif ini masih memerlukan persyaratan khusus, yaitu adanya asas timbal balik (reciprocity basis). ${ }^{12}$ Artinya, kapal Indonesia yang mengisi bahan 
bakar di Korea Selatan tidak akan dikenakan PPN hanya jika Pemerintah Indonesia juga tidak mengenakan PPN terhadap kapal Korea Selatan yang mengisi bahan bakar di Indonesia.

Berdasarkan hal di atas, terlihat bahwa negara-negara tersebut memberikan insentif untuk penyerahan bahan bakar minyak untuk kapal tujuan internasional. Konsumsi atas barang tersebut dianggap sama dengan ekspor barang, sehingga tarif yang dikenakan $0 \%$. Dengan kata lain, negara-negara tersebut tidak mengenakan PPN.

\subsection{Kajian Hukum}

Menurut UU PPN bahan bakar minyak merupakan Barang Kena Pajak (BKP) yang atas penyerahannya terutang PPN. Besarnya adalah $10 \%$ dari harga jual. Ketentuan ini berlaku juga terhadap penyerahan BBM untuk kapal laut tujuan internasional. Padahal, di negara-negara lain pengenaan PPN ini sudah tidak ada lagi. Apakah peraturan yang ada saat ini memungkinkan untuk memberikan fasilitas agar atas penyerahan BBM tersebut tidak dibebani pungutan negara?

Ada dua bentuk fasilitas yang dapat diberikan Pemerintah menurut Pasal 16B UU PPN, yaitu PPN Tidak Dipungut dan PPN Dibebaskan. Fasilitas ini dapat diberikan melalui Peraturan Pemerintah. Dalam Penjelasan Pasal tersebut diatur bahwa kedua bentuk fasilitas tersebut diberikan dengan tujuan untuk berhasilnya sektor kegiatan ekonomi yang mempunyai prioritas tinggi dalam skala nasional, mendorong perkembangan dunia usaha dan meningkatkan daya saing, mendukung pertahanan nasional, serta memperlancar pembangunan nasional. Berdasarkan hal ini, fasilitas PPN dapat diberikan terhadap BBM kapal tujuan internasional karena disamping dapat mendorong perkembang dunia usaha, pemberian fasilitas ini juga dapat meningkatkan daya saing nasional.

Dengan diberikannya fasilitas PPN terhadap BBM kapal tujuan internasional, maka harga BBM tersebut akan menjadi lebih rendah. Akibatnya, harga BBM di Indonesia akan mampu bersaing dengan negara lain. Hal ini akan mendorong kapal-kapal tujuan internasional untuk membeli BBM di Indonesia. Semakin banyak kapal yang bersandar dan mengisi bahan bakar di Indonesia, semakin banyak penjualan yang dilakukan oleh Pertamina melalui agen-agennya. Dengan demikian, agen-agen Pertamina juga akan semakin berkembang.

Kapal-kapal tujuan internasional yang mengisi bahan bakar memerlukan waktu yang relatif lama untuk bersandar. Untuk pengisian BBM di atas 1.000 MT bisa menghabiskan waktu hingga 20 jam untuk setiap kali pengisian. Sambil menunggu pengisian bahan bakar, para awak kapal dapat singgah di kota dekat pelabuhan pengisian bahan bakar. Kedatangan para awak kapal ini tentunya akan membawa dampak ekonomi juga terhadap kehidupan masyarakat. Para awak 
kapal ini akan membelanjakan uangnya di restoran, rumah makan, atau tempattempat perbelanjaan lainnya.

Berdasarkan hal-hal tersebut di atas, pemberian fasilitas PPN atas BBM kapal tujuan internasional sangat sesuai dengan tujuan yang diatur dalam Penjelasan Pasal 16B UU PPN. Oleh karena itu, fasilitas PPN dapat diberikan karena tidak bertentangan dengan tujuan pemberian fasilitas yang diatur dalam Penjelasan Pasal 16B.

Penjelasan Pasal 16B juga menekankan bahwa hendaknya pemberian fasilitas dilakukan dengan sangat terbatas. Terdapat beberapa kriteria yang memungkinkan pemerintah untuk dapat memberikan fasilitas PPN. Dalam UU Nomor 18 Tahun 2000 salah satu kriterianya adalah dalam rangka menampung kemungkinan perjanjian dengan negara atau negara-negara lain dalam bidang perdagangan dan investasi. Dengan kriteria ini pemerintah belum dapat memberikan fasilitas karena harus memenuhi persyaratan adanya perjanjian dengan negara lain dalam bidang perdagangan. Kriteria ini telah direvisi dalam UU Nomor 42 Tahun 2009 yang mulai berlaku sejak 1 April 2010. Dalam Penjelasan UU tersebut tersebut dinyatakan bahwa fasilitas PPN dapat diberikan untuk menampung kemungkinan perjanjian dengan negara lain dalam bidang perdagangan dan investasi, konvensi internasional yang telah diratifikasi, serta kelaziman internasional lainnya.

Negara-negara lain di dunia seperti Singapura, Malaysia, dan Korea Selatan tidak memungut pajak atas penyerahan BBM untuk kapal tujuan internasional. Negara-negara tersebut memperlakukan BBM ini sebagai barang ekspor. Artinya, perlakuan ini sudah menjadi kelaziman internasional. Dengan adanya penambahan kriteria "kelaziman internasional lainnya" dalam Penjelasan Pasal 16B tersebut, Pemerintah sebenarnya sudah dapat memberikan fasilitas PPN atas BBM kapal tujuan internasional sejak 1 April 2010.

Menurut Pasal 16B UU PPN, Pemerintah dapat memberikan fasilitas berupa PPN tidak dipungut atau PPN dibebaskan melalui Peraturan Pemerintah. Jika fasilitas yang diberikan adalah PPN dibebaskan, maka pajak masukan yang dibayar oleh penjual (dalam hal ini Pertamina) tidak dapat dikreditkan dan menjadi unsur biaya. Sebaliknya, dengan fasilitas PPN tidak dipungut, Pertamina dapat mengkreditkan pajak masukan yang telah dibayar, sehingga tidak menjadi unsur biaya. Dengan tidak menjadi unsur biaya, maka PPN tidak lagi menjadi unsur yang melekat dalam harga jual BBM. Penyerahan BBM untuk kapal tujuan internasional menjadi benar-benar bebas dari unsur PPN.

Sebagai perbandingan, Pemerintah sudah memberikan fasilitas PPN tidak dipungut atas penyerahan avtur untuk keperluan penerbangan internasional. Fasilitas ini diberikan melalui Peraturan Pemerintah Nomor 26 Tahun 2005 
Tentang Perlakuan Pajak Pertambahan Nilai atas Penyerahan Avtur untuk Keperluan Penerbangan Internasional yang mulai berlaku sejak 1 Januari $2005^{13}$. Karakteristik avtur untuk penerbangan internasional hampir sama dengan BBM untuk kapal tujuan internasional. Selain keduanya sama-sama dikonsumsi di luar Indonesia, perlakuan pajak terhadap kedua barang tersebut di negara-negara lain juga sama, yakni tidak dikenakan PPN. Oleh karena itu, sudah selayaknya atas penyerahan BBM untuk kapal tujuan internasional mendapat perlakuan yang sama dengan penyerahan avtur untuk penerbangan internasional.

\section{KESIMPULAN DAN SARAN}

\subsection{Kesimpulan}

Berdasarkan hasil kajian yang telah dilakukan, kesimpulan yang dapat diambil adalah:

1. Pemerintah masih memungut PPN sebesar $10 \%$ atas penyerahan BBM untuk kapal tujuan internasional.

2. Negara-negara lain seperti Singapura, Malaysia, dan Korea Selatan tidak memungut PPN atas penyerahan BBM untuk kapal tujuan internasional.

3. Berdasarkan UU Nomor 42 Tahun 2009 Tentang Perubahan Ketiga UU Nomor 8 Tahun 1983 Tentang Pajak Pertambahan Nilai Barang dan Jasa dan Pajak Penjualan atas Barang Mewah yang mulai berlaku 1 April 2010, Pemerintah dapat memberikan fasilitas berupa PPN tidak dipungut atas penyerahan BBM untuk kapal tujuan internasional.

\subsection{Saran}

Berdasarkan kesimpulan di atas, penulis menyarankan agar Pemerintah memberikan fasilitas PPN tidak dipungut atas penyerahan BBM untuk kapal tujuan internasional melalui Peraturan Pemerintah. Hal ini untuk mendorong berkembangnya kegiatan ekonomi dan meningkatkan daya saing nasional.

\section{UCAPAN TERIMA KASIH}

Penulis mengucapkan terima kasih kepada pimpinan di BKF dan LIPI yang telah memungkinkan penulis mengikuti Diklat Fungsional Peneliti Tingkat Pertama Angkatan XVI, kepada Prof. Dr. Erman Aminullah sebagai pembimbing, kepada Dr. Muhammad Hisyam, M.A. sebagai narasumber, dan kepada teman-teman peserta diklat yang telah memberikan masukan-masukan yang berharga. 


\section{DAFTAR PUSTAKA}

1Sukardji, Untung. 2005. Pajak Pertambaha Nilai. Jakarta: Raja Grafindo Persada, hal.3.

2Sukardji, Untung, ibid., hal.22.

${ }^{3}$ Sukardji, Untung, ibid., hal.24.

${ }^{4}$ Nurmantu, Safri. 2003. Pengantar Perpajakan. Jakarta: Granit, hal.36

${ }^{5}$ Brotodihardjo, R. Santoso. 2003. Pengantar Ilmu Hukum Pajak. Bandung: Refika Aditama, hal.212.

${ }^{6}$ Pudyatmoko, Y. Sri. 2006. Pengantar Hukum Pajak. Yogyakarta: Andi offset, hal. $19-21$.

7Undang Undang Nomor 42 Tahun 2009 Tentang Perubahan Ketiga Undang Undang Nomor 8 Tahun 1983 Tentang Pajak Pertambahan Nilai Barang dan Jasa dan Pajak Penjualan atas Barang Mewah.

8Penjelasan Undang Undang Nomor 42 Tahun 2009 Tentang Perubahan Ketiga Undang Undang Nomor 8 Tahun 1983 Tentang Pajak Pertambahan Nilai Barang dan Jasa dan Pajak Penjualan atas Barang Mewah.

${ }^{9}$ Muhammad, Farouk. 2005. Metodologi Penelitian Sosial. Jakarta: PTIK Press dan Restu Agung, hal 89.

${ }^{10}$ Raco, J.R. 2010. Metode Penelitian Kualitatif. Jakarta: Grasindo, hal. 122

11Inland Revenue Authority of Singapore. 2007. Goods and Services Tax. Approved Marine Fuel Trader Scheme. Singapore: IRAS, page 1.

12Ministry of Strategy and Finance. 2010. Korean Taxation, page 165.

13Peraturan Pemerintah Nomor 26 Tahun 2005 Tentang Perlakuan Pajak Pertambahan Nilai atas Penyerahan Avtur untuk Keperluan Penerbangan Internasional. 


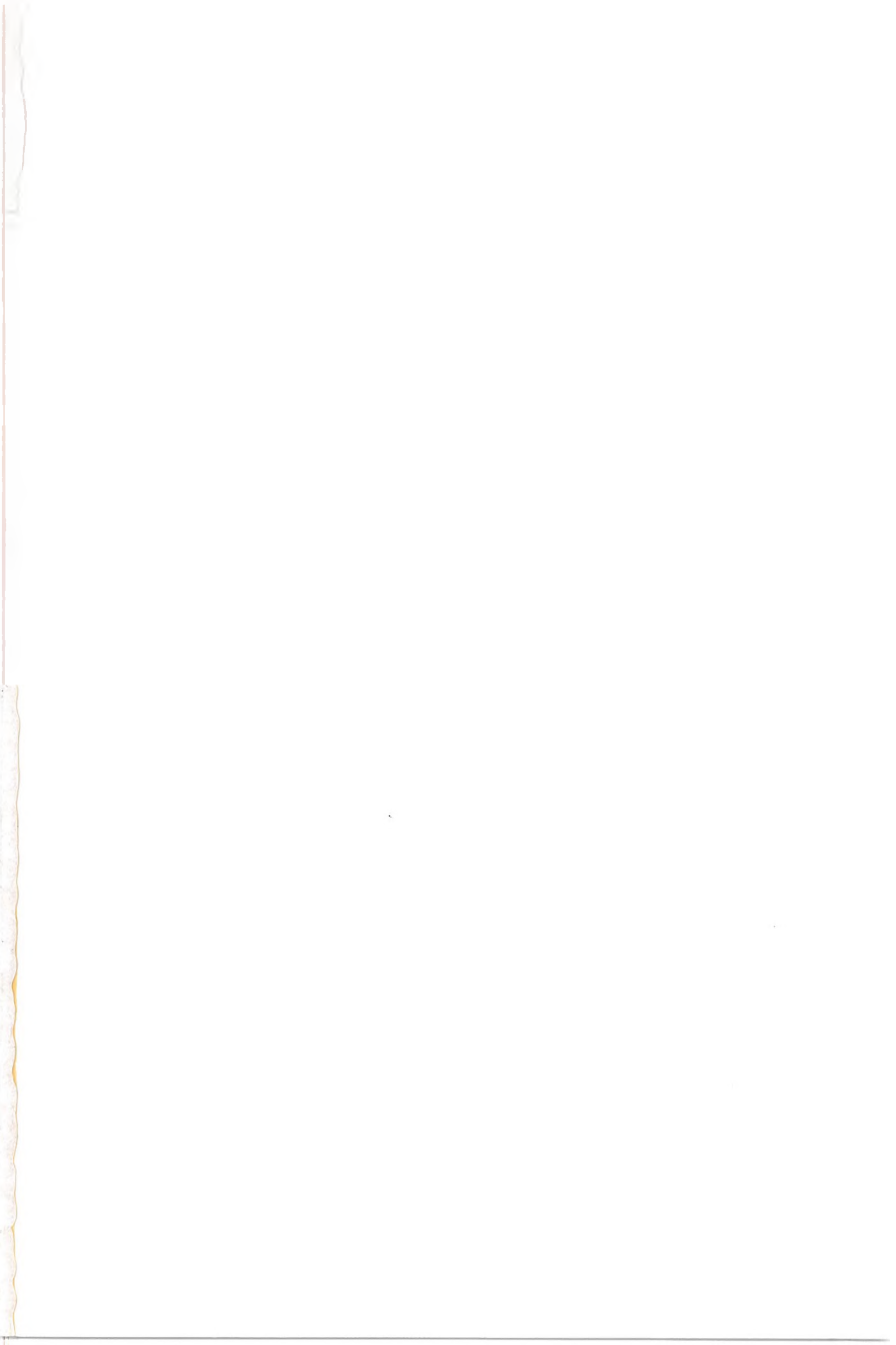

